\title{
Imprensa, Cobertura Eleitoral e Objetividade A eleição de 2000 na capital paulista
}

\author{
Fernando Antônio Azevedo \\ Depto. de Ciências Sociais \\ Universidade Federal de São Carlos
}

\begin{abstract}
Resumo
O texto discute a objetividade jornalística nas coberturas eleitorais da imprensa paulista, tendo como ponto de partida o reconhecimento prévio de que numa "democracia de público" o poder de agenda da mídia demanda a exigência normativa de uma imprensa independente capaz de informar com a maior objetividade o leitor. $\mathrm{O}$ artigo tem como referência empírica a cobertura eleitoral do pleito municipal de 2000 na Capital paulista realizada por três dos grandes jornais locais.
\end{abstract}

Palavras-chave: cobertura jornalística, objetividade, eleições municipais, São Paulo

\begin{abstract}
The text discusses objectivity in the 2000 election press coverage in São Paulo, Brazil. The idea that underlines the paper is that, in reference to Bernard Manin's 'democracy of the public', the strength of the media agenda requires objectivity from an independent press to inform people. The empirical data come from the election press coverage of the three major local newspapers.
\end{abstract}

Key words: newspaper coverage, objectivity, local elections, São Paulo. 


\section{Introdução}

Como se dá a cobertura eleitoral na imprensa brasileira? Uma revisão da literatura dedicada ao tema mostra que a pergunta tem sido respondida, com uma ou outra exceção, de forma crítica. A visão mais comum é a de que tanto a mídia impressa (jornais e revistas) quanto a mídia eletrônica (rádio e TV) são geralmente parciais em suas coberturas e quase sempre favorecem candidatos ligados aos interesses de grupos políticos ou econômicos dominantes.

As evidências de parcialidade e partidarismo da imprensa seriam múltiplas e presentes em nossa história política recente pelo menos desde a campanha eleitoral de 1982, no Rio de Janeiro, que se encerrou com a vitória de Leonel Brizola para o governo estadual apesar da tentativa de fraude na apuração dos votos, episódio em que a TV Globo foi acusada de envolvimento direto. A tendenciosidade da mídia também estaria evidente em vários outros momentos eleitorais, como a célebre edição do debate final entre Lula e Collor realizada pela TV Globo, na eleição de 1989, bem como no apoio praticamente unânime dos principais meios de comunicação de massa ao Plano Real, em 1994, beneficiando indiretamente a candidatura de Fernando Henrique Cardoso. Em 1998, num contexto de crise econômico-financeira, a maior parte da mídia teria favorecido, mais uma vez, e em detrimento do candidato petista, a eleição de FHC. Fora do período eleitoral o exemplo mais citado do comprometimento dos meios de comunicação com as forças conservadoras seria o silêncio da televisão, especialmente a TV Globo, frente ao movimento das "Diretas Já", só rompido quando a mobilização popular tomou as ruas das principais capitais do País.

Apesar das inegáveis evidências de parcialidade da mídia em vários episódios do passado recente (como os que foram citados agora) é algo temerário fazer generalizações sobre a partidarização dos meios de comunicação. Em primeiro lugar porque num país como o nosso, com enormes diferenças regionais em relação à estruturação do mercado de informação e a competitividade dos subsistemas partidários, não se pode falar da imprensa como se ela fosse uma entidade homogênea. Pelo contrário, há graus variados de constrangimentos externos, seja comerciais ou políticos, que delimitam a autonomia e a independência da imprensa em relação aos interesses de grupos econômicos e políticos. Em segundo lugar porque uma revisão das pesquisas e estudos (Rubim \& Azevedo, 1998) sobre o assunto mostra que a alegação sobre a parcialidade da mídia quase sempre é feita de modo impressionista. Além do mais, a relação entre influência da mídia e resultado político, apesar da sua óbvia complexidade metodológica (Howlett, 2000, pp.171-190), é quase sempre analisada como se fosse uma relação direta e linear. Sabemos, porém, que a influência dos meios de comunicação de massa nas atitudes políticas e no comportamento eleitoral é difusa e de difícil verificação empírica, principalmente em proposições do tipo "se $x$, então y" na qual a variável independente é a mídia e a variável dependente o resultado eleitoral (Cf. lyengar e Simon, 2000). Além do 
mais, desde os trabalhos seminais de Lazarsfeld, Berelson e Goudet (1968), a idéia da relação causal e direta entre mensagem e atitude política (contemplada, por exemplo, pela chamada "bullet theory", baseada no mecanismo estímulo-resposta da psicologia behaviorista) foi abandonada em favor de hipóteses mais complexas como a teoria do "two-step" ou "multi-step flow".

Contudo, e apesar da dificuldade em se estabelecer uma relação causal entre influência da mídia e comportamento eleitoral a literatura teórica relevante sobre o tema não nega o poder de agenda dos meios de comunicação de massa e seus efeitos a longo prazo no campo político (veja-se, entre outros, Habermas, 1984; Dahl, 1971; Bourdieu, 1997; Sartori,1998; Schudson, 1995), embora haja grande divergência sobre a natureza (positiva ou negativa) e o limite e alcance desses efeitos (Miguel, 2000). Ao selecionar acontecimentos, personagens, avaliar e criticar idéias e comportamentos ou simplesmente transmitir notícias, a mídia termina configurando temas e hierarquizando questões ao mesmo tempo em que produz enquadramentos favoráveis ou desfavoráveis. Esta capacidade de selecionar e enquadrar os acontecimentos e oferecer uma interpretação sobre eles expressa um poder de agenda capaz de potencialmente transformar a mídia, em determinados momentos, num influente e, às vezes, até mesmo no principal ator político como mostram os episódios que resultaram no impeachment do Presidente Nixon nos USA e de Fernando Collor de Mello no Brasil. Nesse sentido, como lembra Luhmann (1997), a opinião pública se apresenta basicamente como uma estrutura temática configurada pela mídia. Segundo o sociólogo alemão, ao escolher um número limitado de assuntos e acontecimentos a mídia operacionaliza uma redução temática cuja função sociológica fundamental é a simplificação da complexidade social dos temas que são introduzidos, de forma contingente, na opinião pública. Esse processo, que ele define formalmente através do conceito de tematização, reduziria o universo temático da opinião pública essencialmente ao que a mídia publica ou veicula. Obviamente o universo temático é gerado primariamente pelas representações simbólicas elaboradas e postas em circulação pelos atores hegemônicos nas esferas que Luhmann denomina de subsistema político (governo, partidos, políticos), econômico (empresas privadas e estatais) e social (sindicatos e movimentos sociais). Não obstante, como demonstrou a campanha das "Diretas Já", em 1984, certos temas e atores políticos não-hegemônicos (o MST seria um exemplo) às vezes acumulam força social suficiente para romper o eventual silêncio dos meios de comunicação de massa e penetrar no coração da opinião pública.

A noção de agenda-setting, formulada a partir dos trabalhos publicados nos anos 70 por McCombs e Shaw (1972 e 1993), revigorou com novos argumentos a idéia do efeito de agendamento da mídia ao mesmo tempo em que procurou estabelecer modelos de pesquisa capazes de gerar dados e evidências desse efeito pelo confronto entre a agenda da mídia e a agenda do público. Basicamente, a idéia-força desse grupo de pesquisadores é que (1) a mídia ao cobrir determinados assuntos e ignorar outros e ao usar determinados enquadramentos constrói uma representação da realidade; (2) a mídia 
não influencia necessariamente o comportamento do indivíduo sobre um assunto ou questão, mas delimita o conjunto de temas sobre os quais o indivíduo deve pensar e ter uma opinião; (3) a mídia, ao hierarquizar os temas, estabelece prioridades temáticas tanto para os jornalistas quanto para o consumidor de informações e o eleitor. Deste modo, a hipótese da agenda-setting não só revitalizou a crença original sobre a influência da mídia, estabelecida pioneiramente por Lippmann (1997), em 1922, como repercutiu notavelmente no campo de estudos sobre as campanhas políticas à medida que um dos corolários de seus pressupostos é a de que tanto os partidos quanto os candidatos procuram compatibilizar a agenda da campanha com a agenda da mídia e a do público.

Em resumo, há um consenso razoavelmente estabelecido entre diferentes autores e tradições teóricas sobre a influência da mídia (positiva/negativa, variando em grau e intensidade dependendo da perspectiva analítica) na configuração (tematização, agenda, etc.) do campo político (esfera pública, opinião pública, etc.) e, por extensão, dos embates eleitorais. O reconhecimento do poder de agenda da mídia certamente autoriza e legitima a exigência normativa de uma imprensa independente (definida restritivamente, para os propósitos desse artigo, como uma imprensa desvinculada dos interesses partidários e eleitorais, mas certamente também dos grupos de interesses econômicos) capaz de potencialmente informar com a maior objetividade possível o leitor. Este é o ponto central que esse texto pretende se ocupar tendo como referência empírica o pleito municipal de 2000 em São Paulo: a cobertura eleitoral da grande imprensa paulista está mais próxima ou mais distante do princípio normativo de uma imprensa apartidária e independente? Uma resposta à questão, no atual estágio da literatura brasileira sobre o tema, demanda a produção de evidência empíricas que possam ser sustentadas teoricamente e que contribua para a montagem de um quadro regional comparativo do comportamento da mídia diante do processo eleitoral. 


\section{A democracia do público}

Num artigo sobre a evolução da democracia representativa Manin (1995, p.26) caracteriza as sociedades de massa como democracias do público (no sentido de audiência) nas quais :

...os candidatos se comunicam diretamente com seus eleitores através do rádio e da televisão, dispensando a mediação de uma rede de relações partidárias... (e)... a televisão realça e confere uma intensidade especial à personalidade dos candidatos.

Numa democracia do público, segundo o autor citado, a identidade social e a identificação partidária perdem importância relativa na determinação do voto e "o eleitorado se apresenta, antes de tudo, como um público que reage aos termos propostos no palco da política" (p. 28), ou seja, "...votando de acordo com os problemas e as questões postas em jogo em cada eleição" (p. 32). Neste contexto os meios de comunicação de massa ganham não só uma posição estratégica na produção da visibilidade do campo político como também dividem com o parlamento e os partidos a posição de principal fórum do debate público. Essa transformação, essencial para a formação de uma democracia do público, demandou historicamente a superação da imprensa de opinião, fortemente partidarizada, e um progressivo processo de distanciamento e neutralidade dos jornais modernos em relação aos partidos políticos. Apoiado na experiência européia e francesa Manin lembra que, hoje, os partidos políticos por razões econômicas e tecnológicas não são mais proprietários de jornais de grande circulação e que o rádio e a televisão não têm filiação ou orientação partidária. Como resultado do distanciamento da mídia em relação às clivagens partidárias:

...as pessoas receberiam as mesmas informações sobre um dado assunto, a despeito de suas preferências políticas. Isso não significa que os assuntos ou os fatos - diferentemente dos julgamentos - sejam percebidos de maneira 'objetiva', sem distorções, mas simplesmente que eles são percebidos de maneira relativamente uniforme através de um amplo espectro das preferências políticas. (idem, ibidem, p.30)

Para apoiar sua argumentação o autor faz referências a duas situações históricas em que a opinião pública desempenhou um papel fundamental, uma na França do final do século XIX e outra nos anos setenta do último século: os casos Dreyfus e Watergate. Citando um estudo clássico de Lang \& Lang (1983, p.31), ele lembra que no caso Dreyfus a percepção dos fatos era fortemente partidarizada devido à existência de uma imprensa de opinião controlada por correntes políticas antagônicas enquanto que, no escândalo Watergate, os americanos, independentemente de suas preferências partidárias, tinham basicamente a mesma compreensão dos fatos por conta da inexistência de uma imprensa partidária. 


\section{Democracia de público no Brasil: partidos e imprensa}

A literatura sobre partidos reconhece a debilidade do sistema partidário brasileiro e a grande autonomia dos políticos em relação às agremiações partidárias enquanto que, por sua vez, a literatura produzida na área de comunicação chama a atenção para a crescente importância da mídia no nosso processo eleitoral. Para alguns autores a debilidade é explicada historicamente pela descontinuidade do nosso sistema partidário provocada pelas inúmeras rupturas institucionais como a Revolução de 30 , o EstadoNovo, o Al-5 e a redemocratização. Como decorrência, em cinqüenta anos tivemos três sistemas partidários distintos, dois períodos multipartidários e um bipartidarismo compulsório (Schmitt, 2000). Estas circunstâncias adversas teriam impedido não só a formação de uma cultura política partidária (Souza, 1976) como um processo de socialização política baseada em lealdades partidárias que pudessem ser transmitidas de geração a geração. Por outro lado, como chama a atenção Mainwaring (1991), a natureza do nosso sistema eleitoral (representação proporcional de lista aberta, mecanismo do candidato nato, etc.) combinada com uma legislação partidária permissiva (que permite uma fácil migração partidária) produz fortes incentivos à autonomia dos políticos frente aos partidos e reforça o comportamento individualista dos candidatos. Estas características associadas às novas configurações assumidas pelas campanhas eleitorais após a redemocratização (centrada basicamente na mídia eletrônica) estimulariam a comunicação direta do candidato com o eleitor. Nesse processo deve ser lembrado o papel peculiar e paradoxal exercido pelo Horário Gratuito de Propaganda Eleitoral (HGPE): ao mesmo tempo em que democratiza a campanha eleitoral à medida que possibilita o acesso gratuito de todos os partidos e candidatos à TV e ao rádio, O HGPE, pelas suas características audiovisuais (ver Albuquerque, 1999a), favorece uma crescente personalização da competição eleitoral em detrimento da imagem partidária e do debate programático ou ideológico. Em resumo, a combinação entre a debilidade histórica dos partidos brasileiros, a existência de uma legislação eleitoral e partidária que incentiva a ação individual dos candidatos e a centralidade dos meios de comunicação de massa no processo eleitoral, especialmente a TV, caracterizariam a nossa atual prática democrática como uma democracia do público.

Por conta das vicissitudes históricas do nosso sistema partidário a grande imprensa brasileira se desenvolveu, ao contrário da França ou dos Estados Unidos, formalmente separada dos partidos políticos. É claro que essa desvinculação formal não impediu a articulação de nossos principais jornais com os interesses das frações oligárquicas no poder ou na oposição nem a proliferação de uma "imprensa de opinião" bastante ativa que sobreviveu até, pelo menos, os anos cinqüenta, sessenta do último século. Até o fim do período populista (1964) era comum que veículos importantes defendessem explicitamente interesses eleitorais e posições de correntes políticas e ideológicas, a exemplo dos jornais Ultima Hora (ligado a Getúlio Vargas e depois a João 
Goulart), Tribuna da Imprensa (Carlos Lacerda) e O Globo e O Estado de São Paulo (ambos conservadores e na oposição ao governo Goulart). Fora do eixo Rio-São Paulo esta imprensa comprometida com os interesses econômicos ou políticos de frações da elite dominante se tornou dominante: em praticamente todos estados da Federação os principais grupos políticos locais controlavam (e, de acordo com dados publicados recentemente, ainda controlam) direta ou indiretamente os grandes jornais regionais e as emissoras de rádio e TV.

Entretanto, após o interregno autoritário (1964-1985) e em função das profundas mudanças ocorridas nas últimas décadas na tecnologia e no mercado de informação, parte da grande imprensa brasileira ressurgiu profissionalizada e redefinida em sua relação com a sociedade política como chama a atenção Albuquerque (1999b, p.2):

De um modo geral, os órgãos da grande imprensa brasileira são hoje muito mais independentes de partidos ou facções políticas do que no passado, comprometidos que estão com a lógica empresarial capitalista (...) Além do mais, a multiplicação de fóruns de debate profissional - como por exemplo a revista Imprensa e organizações voltadas para o 'media criticism' como o Observatório da Imprensa e o Instituto Gutemberg - sugere ter havido nos últimos anos um significativo avanço na constituição de uma identidade profissional jornalística baseada numa ética do serviço público.

Segundo o autor citado este novo jornalismo teria como modelo ético e profissional o 'jornalismo independente' norte-americano e seus valores básicos como objetividade, neutralidade, imparcialidade, compromisso com os fatos e o leitor-cidadão e foco no serviço público.

\section{Duas premissas sobre o jornalismo apartidário}

Não há dúvida de que o jornalismo moderno brasileiro nada tem em comum com o velho jornalismo partidário do período populista. Todavia, o paradigma do jornalismo independente não é uma realidade disseminada em todos os quadrantes e veículos do País e é mais do que razoável supor que pelo menos duas premissas sejam condições necessárias para que ele se estabeleça :

\section{1) Um mercado de informação competitivo}

Vários autores, entre os quais Hoffman (1985), enfatizam a importância da competição comercial entre os veículos como um dos fatores exógenos mais decisivos para a adoção da prática de um jornalismo independente. $O$ argumento-chave é que a disputa pelas verbas publicitárias num ambiente empresarialmente competitivo produz como efeito direto uma concorrência acirrada pela audiência (que é o parâmetro pelo qual o mercado publicitário se guia para alocar suas verbas) e, portanto, indiretamente a busca de um produto competitivo (a notícia) capaz de ampliar a audiência. Por sua vez, a 
definição desse produto estaria associada a noções ligadas a fatores endógenos como a formação e a identidade profissional (Tuchman, 1978 e 1993), envolvendo conceitos como independência, credibilidade, objetividade, profissionalização, prestação de serviços e compromisso com o leitor, etc. Deste modo, a adoção da lógica empresarial - ao contrário da argumentação clássica de Habermas sobre a degradação dos periódicos na sociedade burguesa e parodiando a expressão de Mandeville (vícios privados, virtudes públicas) - estimularia a desvinculação e a neutralização dos jornais em relação aos interesses políticos e partidários.

Considerando-se relevante e legítimo o argumento da competição comercial como um dos indutores da independência jornalística, e tomando-se o caso de São Paulo, os dados que se seguem sugerem que o mercado de informação paulista não só é bastante competitivo do ponto de vista empresarial como os principais jornais editados naquele estado são percebidos como órgãos com credibilidade jornalística. A Tabela 1 mostra que entre os dez principais jornais incluídos no ranking dos principais veículos por faturamento bruto no Brasil encontram-se nada menos do que seis empresas paulistas contra três cariocas e uma mineira, indicando, deste modo, um alto nível de competitividade entre os principais jornais de São Paulo.

\section{TABELA 1}

Ranking dos principais jornais do Brasil por faturamento bruto (Janeiro a junho de 2000)

\begin{tabular}{|c|c|}
\hline & JORNAL \\
\hline 1 & O ESTADO DE SÃO PAULO (SP) \\
\hline 2 & FOLHA DE SÃO PAULO (SP) \\
\hline 3 & O GLOBO (RJ) \\
\hline 4 & DIÁRIO POPULAR (SP) \\
\hline 5 & O DIA (RJ) \\
\hline 6 & JORNAL DA TARDE (SP) \\
\hline 7 & DIÁRIO DO GRANDE ABC (SP) \\
\hline 9 & GAZETA MERCANTIL (SP) \\
\hline 10 & JORNAL DO BRASIL (RJ) \\
\hline
\end{tabular}

Fonte: IBOPE - MONITOR

Por sua vez o Gráfico 1 mostra a percepção da credibilidade, um dos principais valores perseguidos pelo jornalismo que reivindica uma posição independente e um dos mais importantes indicadores na avaliação da qualidade jornalística. Numa pesquisa realizada pela Consultoria Jaime Troiano, em setembro de 2001, junto a uma amostra de cinco mil anunciantes, publicitários e fornecedores do mercado nacional de informação, as três primeiras posições no item "credibilidade" (cada entrevistado pôde dar mais de uma resposta) foram ocupadas por veículos paulistas. 
GRÁFICO 1

Credibilidade (\%) dos jornais brasileiros (Set/2001)

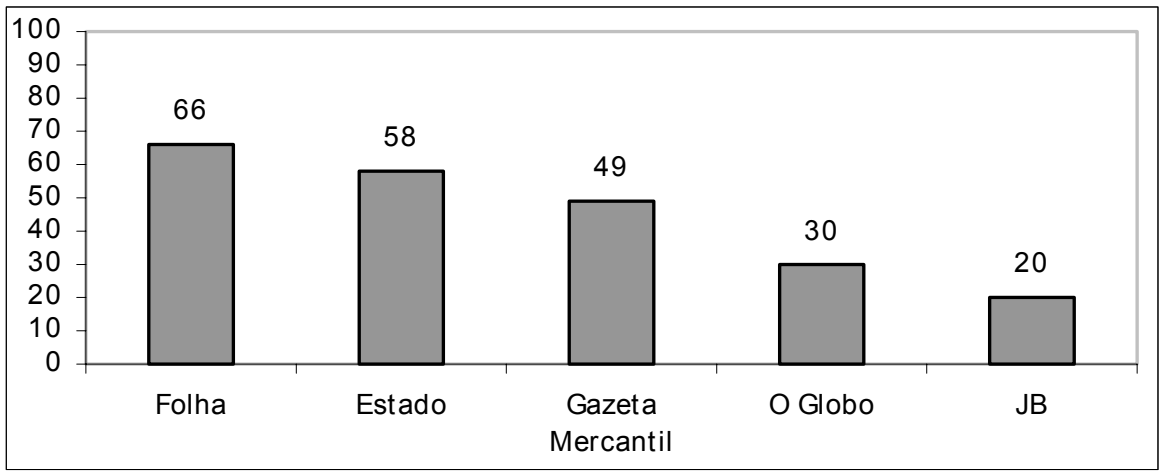

2) Um subsistema partidário do tipo poliárquico (poliarquia eleitoral)

O termo poliarquia eleitoral é usado com o sentido dado por Sartori (1987, pp.212213) a partir do conceito original de poliarquia elaborado por Dahl (1971). Como se sabe, Dahl utiliza a noção de democracia para denotar um "sistema ideal" (conceito normativo) e emprega a noção de poliarquia para caracterizar uma situação real (conceito instrumental), possibilitando, desta forma, a elaboração de modelos comparativos entre sistemas competitivos e não-competitivos e o grau de democracia entre os sistemas competitivos. Para ele, um sistema político se transforma efetivamente em poliárquico quando, além dos pré-requisitos democráticos mínimos (liberdades básicas, rotatividade no poder, respeito à minoria e à oposição, etc.) ele é também competitivo (do ponto de vista eleitoral) e participativo (do ponto de vista da representação), ensejando, desta forma, o controle recíproco dos atores políticos. Sartori, ao usar a expressão poliarquia eleitoral, sublinha e enfatiza a idéia de competição e competitividade entre diversos grupos políticos no processo eleitoral. O ponto crucial na noção de poliarquia eleitoral é exatamente o controle recíproco dos atores políticos (obviamente só possível num sistema ou subsistema formado por vários grupos competitivos), situação que dificulta ou impede o uso exclusivo da mídia por um dos competidores, reduzindo ou anulando, em conseqüência, os constrangimentos externos nesse sentido.

O Gráfico 2 mostra a competitividade do subsistema partidário paulista: ao longo de dezoito anos e dez episódios eleitorais cinco partidos, quatro dos quais ainda hoje atores relevantes no jogo eleitoral regional (PMDB, PSDB, PPB e PT), chegaram ao governo municipal da Capital ou ao governo estadual. Ainda que os dados revelem uma polarização segundo a natureza do pleito (PT e PPB no plano municipal e PMDB e PSDB na esfera estadual) é evidente que a dinâmica eleitoral paulista se enquadra na noção de uma poliarquia eleitoral. 


\section{GRÁFICO 2}

Partidos e vitórias eleitorais - Governo do Estado e Prefeitura da Capital (1982-2000)

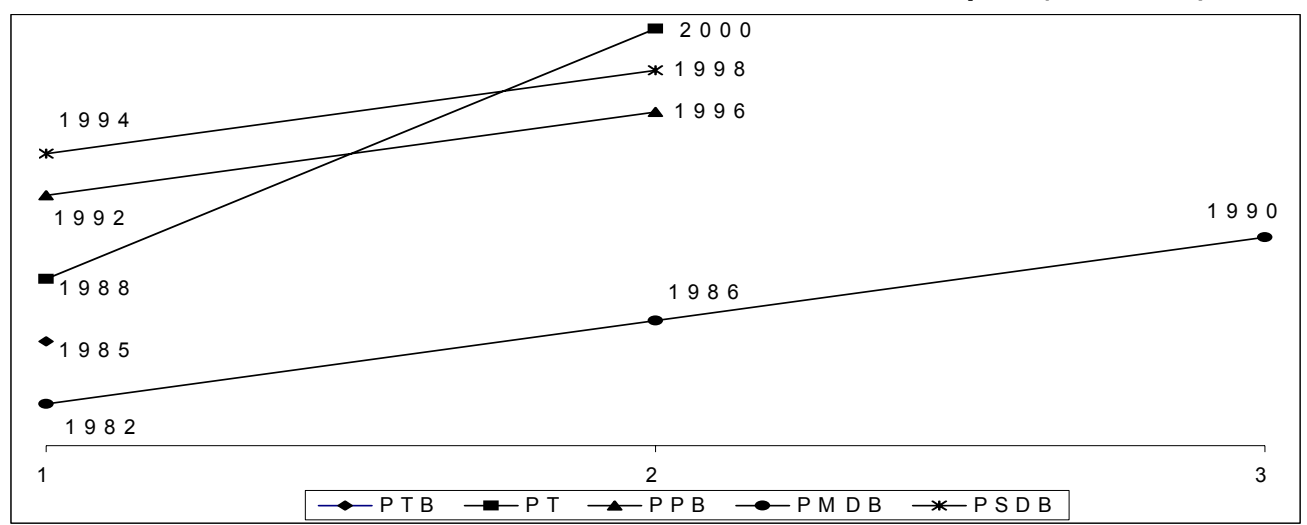

Em resumo, e concluindo a argumentação desenvolvida até o momento, este trabalho tem como ponto de partida a noção de democracia de público (que implica na existência de um jornalismo objetivo e apartidário) e apoia-se nas premissas enunciadas nos parágrafos anteriores para analisar a cobertura eleitoral dos jornais paulista sobre o pleito municipal de 2000 na Capital. Espera-se, de acordo com as premissas estabelecidas, que a cobertura dos principais jornais paulistas seja apartidária e objetiva em relação às candidaturas em disputa.

\section{Informações metodológicas}

Além de competitiva empresarialmente a grande imprensa paulista é uma das mais segmentadas do país. Os tradicionais diários Folha de $S$. Paulo e $O$ Estado de $S$. Paulo disputam acirradamente o público leitor da classe A e B. Entre os jornais com acento popular (classes C e D) a disputa pela audiência era travada, durante a campanha eleitoral de 2000, entre o Diário Popular (hoje sob o controle das Organizações Globo e relançado com o título de Diário de São Paulo) e o então recém-lançado Agora, editado pelo grupo Folha. Entre os jornais especializados em economia e finanças a tradicional Gazeta Mercantil e o recente Valor Econômico (publicado em parceria pelo grupo Folha e Organizações Globo) disputam a liderança da audiência. Há, ainda, um grande número de 
publicações com periodicidade variável (semanal, quinzenal, mensal) que circula na Grande São Paulo ou restrito a determinados bairros ou distritos da Capital.

Para rastrear a cobertura eleitoral de 2000 e confrontar o modelo normativo de um jornalismo objetivo e apartidário com a prática jornalística efetivamente desenvolvida foram escolhidos três diários da grande imprensa paulista: a Folha de S. Paulo e o Estado de S. Paulo (público-alvo A e B) e o jornal Agora (público-alvo C e D). O período de observação cobriu todas as edições diárias dos referidos jornais durante a campanha do $1^{\circ}$ turno eleitoral ( 01 de julho a 01 de outubro) e do $2^{\circ}$ turno eleitoral (02 a 29 de outubro). O material analisado (textos, fotos e charges), incluiu todas as matérias do primeiro caderno dos referidos veículos, bem como o caderno Cidades (Estadão) e Cotidiano e Eleições (Folha de S. Paulo). Obviamente a inclusão dos cadernos locais foi determinada pela natureza municipal da competição eleitoral. Duas dimensões básicas foram contempladas: a visibilidade dos candidatos (consideradando apenas os mais relevantes do ponto de vista político e eleitoral) e a valoração das matérias em relação às candidaturas. ${ }^{1}$

A dimensão valorativa definiu a natureza da cobertura eleitoral, se objetiva e apartidária ou não. Para trabalhar a dimensão valorativa se convencionou aplicar um sinal de valência (positivo, neutro ou negativo) em cada matéria (texto) ou imagem (foto/charge) levando-se em conta o saldo das informações, se benéfica, prejudicial ou neutra à candidatura de cada postulante. Adotou-se, com algumas modificações, os critérios utilizados pela Folha de São Paulo para definir a valência das matérias em relação aos candidatos: + (Positivo) matéria sobre ou com o candidato reproduzindo programa de governo; promessas; autodeclaração ou declarações do autor da matéria ou de terceiros (pessoas ou entidades) favoráveis (contendo avaliação de ordem moral, política ou pessoal) ao candidato; reprodução de ataques do candidato a concorrentes; - (Negativo): matéria reproduzindo ressalvas, críticas ou ataques (contendo avaliação de ordem moral, política ou pessoal) do autor da matéria, de candidatos concorrentes ou de terceiros a algum candidato; * (Neutro): agenda do candidato, resultados de pesquisas, citação sem avaliação moral, política ou pessoal do candidato.

Finalmente, para a interpretação final dos dados da dimensão valorativa foi estabelecido que se o percentual de matérias neutras fosse igual ou maior do que $50 \%$ a cobertura seria considerada objetiva e apartidária.

\footnotetext{
${ }^{1} \mathrm{O}$ modelo de coleta de dados adotado com algumas modificações pela pesquisa foi originalmente proposto por Marcus Figueiredo, pesquisador e Coordenador do DOXA - Laboratório de Pesquisa em Comunicação Política e Opinião Pública (IUPERJ).
} 


\section{Os números da pesquisa}

\section{$1^{\circ}$ Turno}

Como se pode ver no Gráfico 3 a Folha de S. Paulo, como era de se esperar pela prioridade que normalmente concede à cobertura política (expressa pela edição de diária de um caderno especial sobre as eleições), foi o veículo que mais espaço concedeu à competição eleitoral, sendo seguido pelo seu concorrente direto, O Estado de S. Paulo, que tradicionalmente dedica mais espaço ao noticiário econômico e internacional. Por sua vez o jornal Agora, cuja linha popular enfatiza o noticiário policial e as notícias do mundo do entretenimento, foi quem menos abriu espaço para a corrida eleitoral.

\section{GRÁFICO 3}

Espaço (\%) dedicado à campanha municipal de São Paulo - $1^{\circ}$ turno

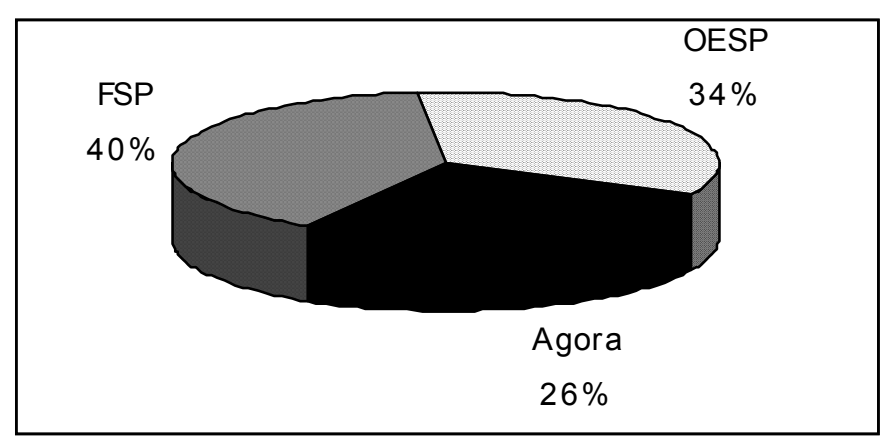

Durante a campanha do primeiro turno eleitoral a atenção dispensada (Gráfico 4) pelos três jornais aos candidatos foi correspondente, com ligeiras variações, às posições ocupadas pelos competidores nas pesquisas de intenção de voto. Esta constatação confirma a percepção que se tem desde pleitos anteriores (Azevedo, 2000) de que a cobertura eleitoral da mídia vem sendo cada vez mais pautada pelas pesquisas de intenção de voto, implicando não só no crescente enquadramento da disputa política pela perspectiva de um horse race (Cf. Karbel,1994), como também numa "espiral do silêncio" (Noelle-Neumann, 1995) que limita as opções do eleitor aos mais votados nas sondagens. Como todos se recordam, Marta liderou todas as pesquisas de opinião de ponta a ponta e 
sua presença no segundo turno era uma certeza entre todos os analistas políticos. Maluf e Alckmin disputaram acirradamente o segundo lugar e a presença no segundo turno, sendo ambos assediados apenas por Tuma (quase no final da campanha) e por Erundina (no início do processo eleitoral, quando a ex-prefeita chegou a ocupar o segundo lugar nas intenções de voto). Entre todos os candidatos o mais citado foi Paulo Maluf, em parte por conta de seu passado político e personalidade polêmica; de outro lado pela sua vinculação política com o então prefeito Celso Pitta, alvo de recorrentes denúncias de corrupção no período pré-eleitoral. Contudo, como se verá mais adiante, ele também foi o candidato que recebeu mais referências negativas nos jornais pesquisados.

\section{GRÁFICO 4}

Número de citações (texto e imagens) - $1^{\circ}$ turno

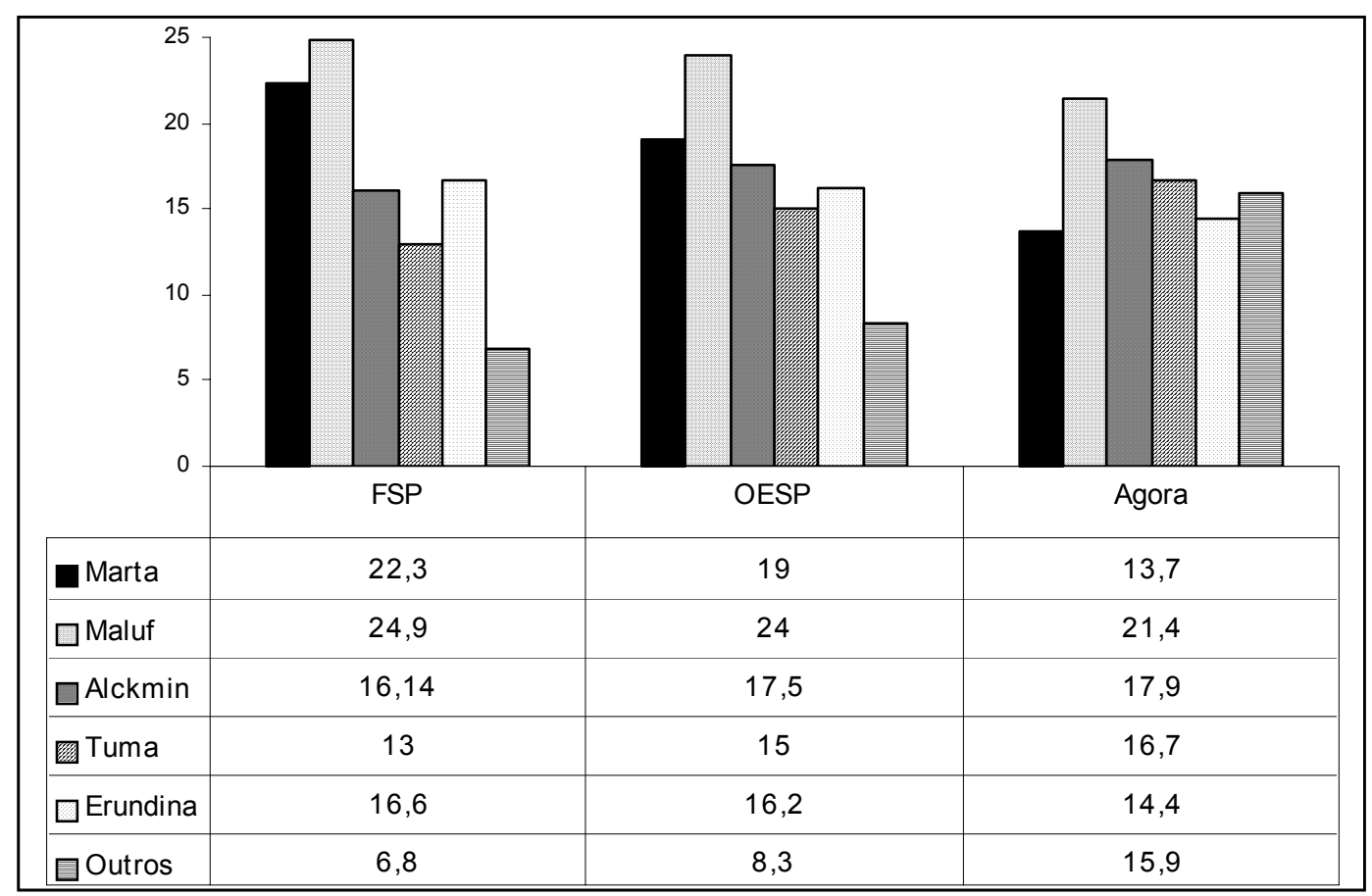


Os três gráficos seguintes mostram a valência das matérias em relação às principais candidaturas, ou seja, o enquadramento que cada um dos postulantes recebeu dos jornais pesquisados.

\section{GRÁFICO 5}

Valência (\%) FSP - $1^{\circ}$ turno

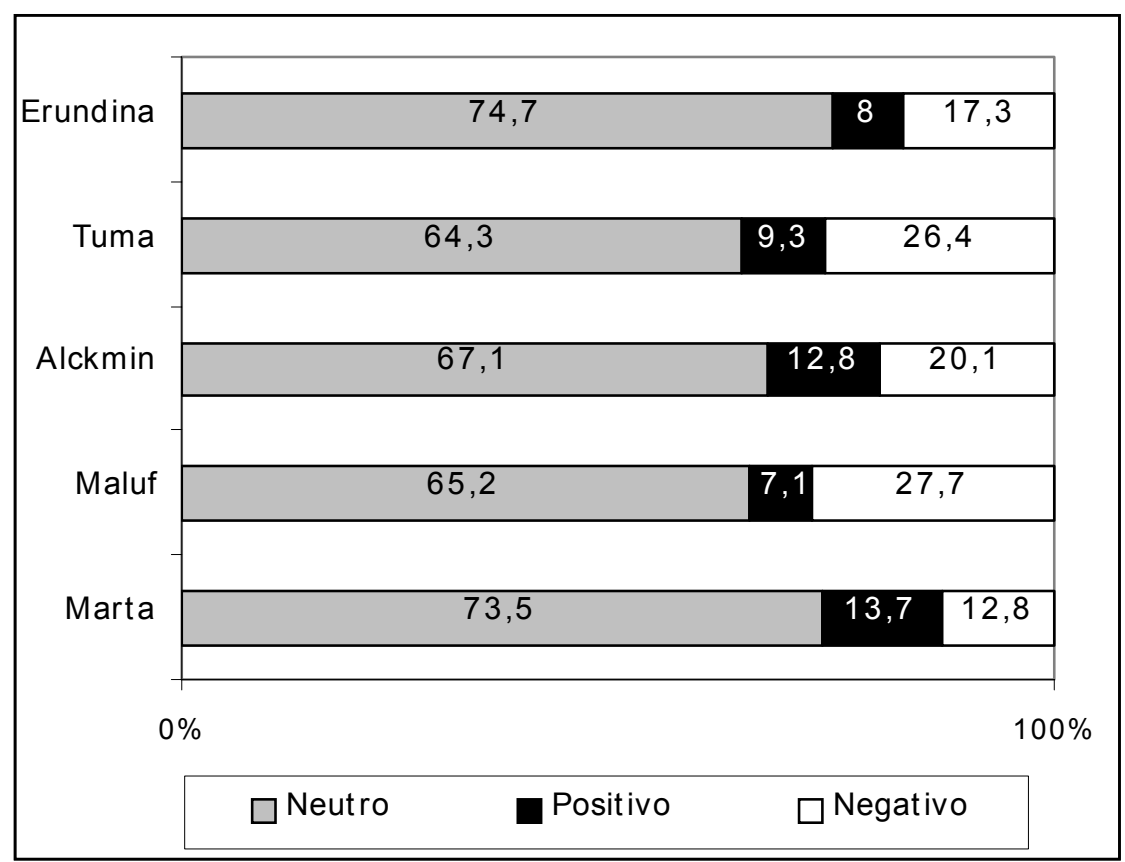

$\mathrm{Na}$ Folha de São Paulo as matérias neutras superam com folga a soma das matérias positivas e negativas em relação às candidaturas de todos os competidores. Em outras palavras, a cobertura do $1^{\circ}$ turno se manteve dentro do padrão de objetividade definida pela pesquisa. Como se pode observar no Gráfico 5 as candidaturas de Erundina e Marta obtiveram os maiores percentuais de matérias neutras. Confrontando as matérias positivas e negativas, Marta e Alckmin foram os candidatos que receberam mais menções positivas enquanto que Maluf e Tuma ganharam mais referências negativas. $O$ alto percentual de Maluf, como já foi explicado, deveu-se ao seu passado político e suas vinculações com o então prefeito Pitta; quanto ao Tuma, no momento em que apresentava um crescimento nas intenções de voto, ele passou a sofrer ataques que terminaram sendo reproduzidos na mídia. Finalmente, embora Erundina tenha recebido o maior número de matérias neutras, foi Marta quem mais se beneficiou da cobertura do jornal à medida que recebeu mais matérias positivas e menor percentual de matérias negativas. 


\section{GRÁFICO 6}

Valência (\%) OESP - $1^{\circ}$ turno

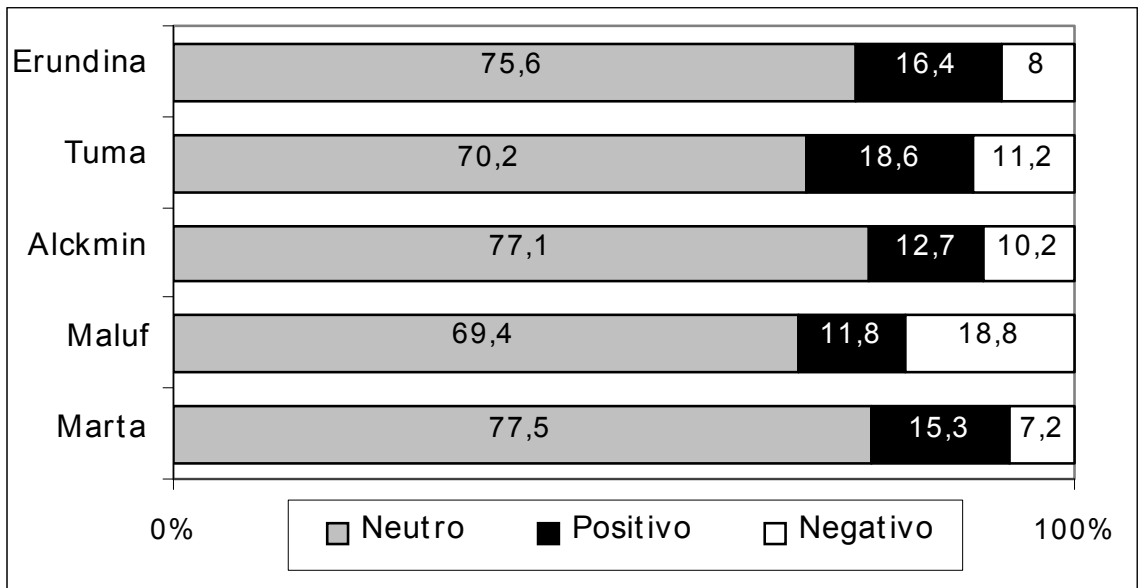

Em O Estado de S. Paulo a cobertura também foi objetiva, de acordo com os critérios estabelecidos pela pesquisa, mas o jornal apresentou, em confronto com seu concorrente direto, um percentual mais expressivo de matérias neutras em relação a todas candidaturas. Também comparativamente o Estadão foi o jornal menos crítico. Mas, como na Folha de São Paulo, Maluf e Tuma (sendo seguido de perto por Alckmin) receberam o maior percentual de matérias críticas, embora, e ao contrário da Folha, a distância entre o percentual de Maluf e Tuma tenha sido significativa. Esse dado é importante quando observamos as matérias positivas, pois foi Tuma, seguido de Marta, quem recebeu mais matérias favoráveis.

\section{GRÁFICO 7}

Valência (\%) Agora - $1^{\circ}$ turno

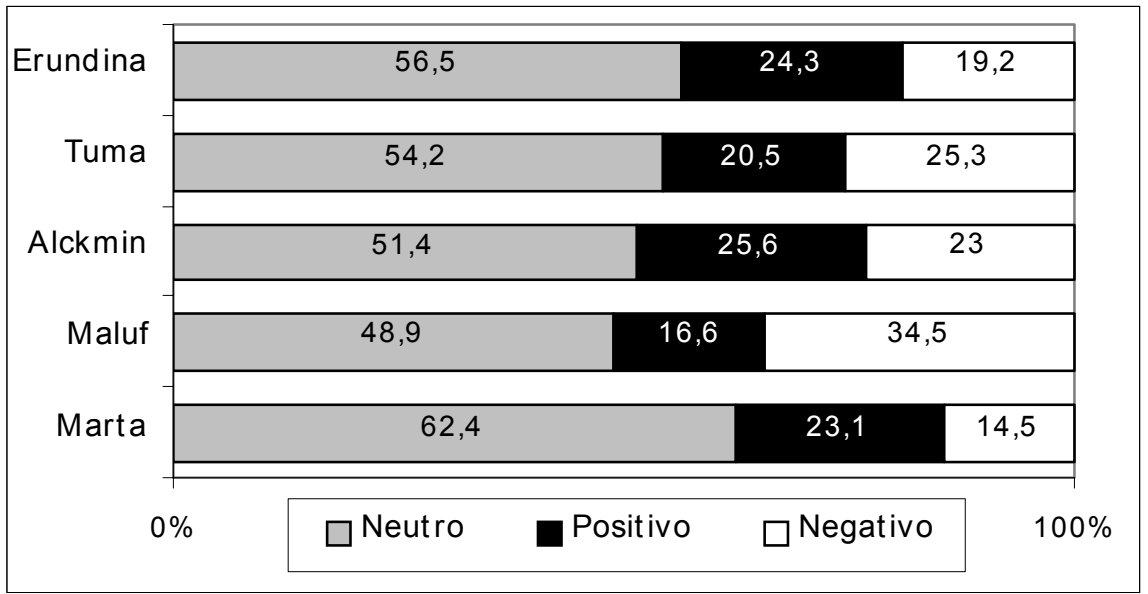


O jornal Agora, provavelmente pelo seu acento popular (marcado por uma linha editorial mais agressiva e uma sintaxe baseada no uso intensivo de adjetivos), desviou-se do padrão observado nos jornais voltados para o público A e B. Como se pode observar no Gráfico 7, o referido diário foi quem publicou menos matérias neutras, tendo sido, também, o único veículo cuja cobertura ficou aquém dos $50 \%$ de matérias neutras (em relação à candidatura de Maluf) estipulados pela pesquisa para definir a objetividade. Mais uma vez Maluf e Tuma foram os candidatos que receberam mais críticas, enquanto que Alckmin e Erundina (seguido de perto por Marta) obtiveram as matérias mais favoráveis às suas candidaturas. Comparativamente, o jornal foi o mais crítico de todos, mas, em compensação, foi quem mais produziu matérias positivas. Sem dúvida, essa particularidade deve ser mais uma vez atribuída à sua natureza editorial.

Em resumo, o conjunto dos dados mostra que a cobertura eleitoral do primeiro turno pelos jornais pesquisados (com exceção do Agora em relação à candidatura Maluf) se deu dentro do padrão de objetividade definido pelos critérios estabelecidos pela pesquisa.

\section{$2^{\circ}$ Turno}

O espaço dedicado à campanha do $2^{\circ}$ turno foi praticamente o mesmo alocado por todos os veículos durante o $1^{\circ}$ turno, com a Folha de São Paulo, mais uma vez por conta do seu caderno eleitoral, dando um pouco mais de atenção ao pleito do que seu concorrente direto e o seu irmão menor.

\section{GRÁFICO 8}

Espaço (\%) dedicado à campanha municipal de São Paulo - $2^{\circ}$ turno

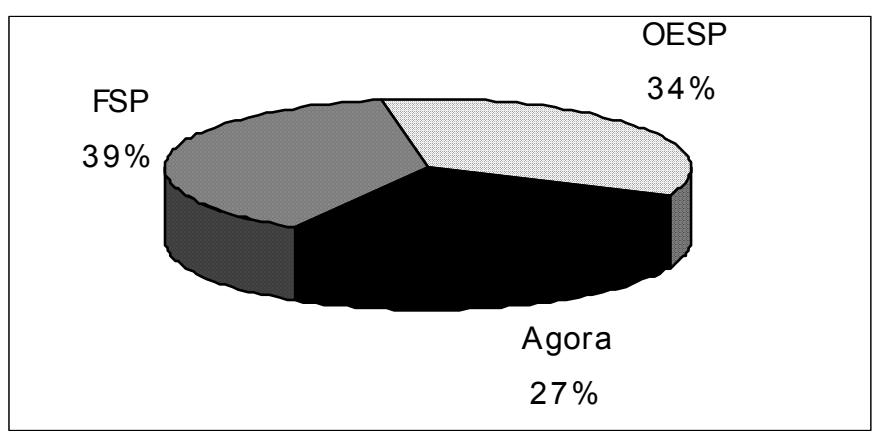

Os dois candidatos que disputaram o turno final tiveram, com ligeiras variações, a mesma visibilidade nos três veículos. Mais uma vez Paulo Maluf foi o mais citado, mas, como ocorreu no turno anterior, a razão disto se deveu em boa parte às matérias negativas ao contrário da candidata do PT, como veremos mais adiante. De qualquer maneira a diferença de visibilidade entre Maluf e Marta nos três jornais é mínima, como se pode observar no gráfico seguinte. 


\section{GRÁFICO 9}

Número de citações (texto e imagem) - $2^{\circ}$ turno

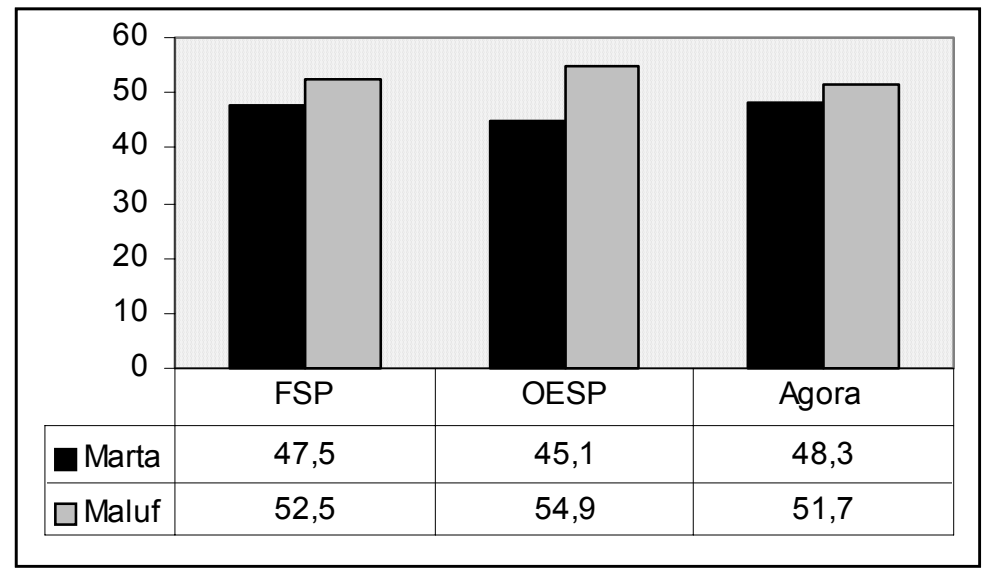

No que diz respeito à valência os dados da cobertura do $2^{\circ}$ turno não reafirmaram a objetividade encontrada durante o primeiro escrutínio. Dos três jornais pesquisados apenas a Folha de S. Paulo se manteve dentro do padrão de objetividade definido pela pesquisa. Apesar disto, uma análise mais detalhada mostra que a Folha concedeu mais matérias neutras a Marta $(87,7 \times 77)$ e quase 2,5 vezes mais matérias negativas a Maluf $(18,7 \%$ a $7,2 \%)$. O Estado de S.Paulo publicou mais matérias neutras $(55,1 \%)$ em relação à candidatura de Marta, porém, em relação ao candidato pepebista, predominaram a soma das citações negativas e positivas sobre as neutras. Comparando-se as matérias negativas do Estadão em relação aos dois candidatos (33,3\% para Maluf e 17,1\% para Marta) percebe-se que Maluf ganhou em relação à candidata petista o dobro de matérias negativas. A postura crítica do Estado de S.Paulo em relação ao candidato não chega a ser uma surpresa para quem acompanhou de perto a campanha eleitoral: a rádio Eldorado (vinculado ao grupo editorial do Estadão) veiculou intensamente antes e durante a campanha mensagens conclamando abertamente os eleitores a não sufragar Paulo Maluf. Quanto ao jornal Agora, coerente com sua linguagem mais direta, foi o único que publicou mais matérias negativas e positivas do que neutras para os dois candidatos. No caso de Maluf, as matérias negativas suplantam as neutras e positivas; enquanto que no caso da Marta ocorre o inverso: as matérias neutras suplantam as positivas e estas as negativas, produzindo, assim, um saldo positivo para a candidata petista.

Em síntese, dos três jornais apenas um (Folha de S. Paulo) se manteve dentro do padrão de objetividade definido pela pesquisa e em todos eles a candidata petista recebeu mais matérias positivas e neutras e menos matérias negativas do que seu concorrente. 


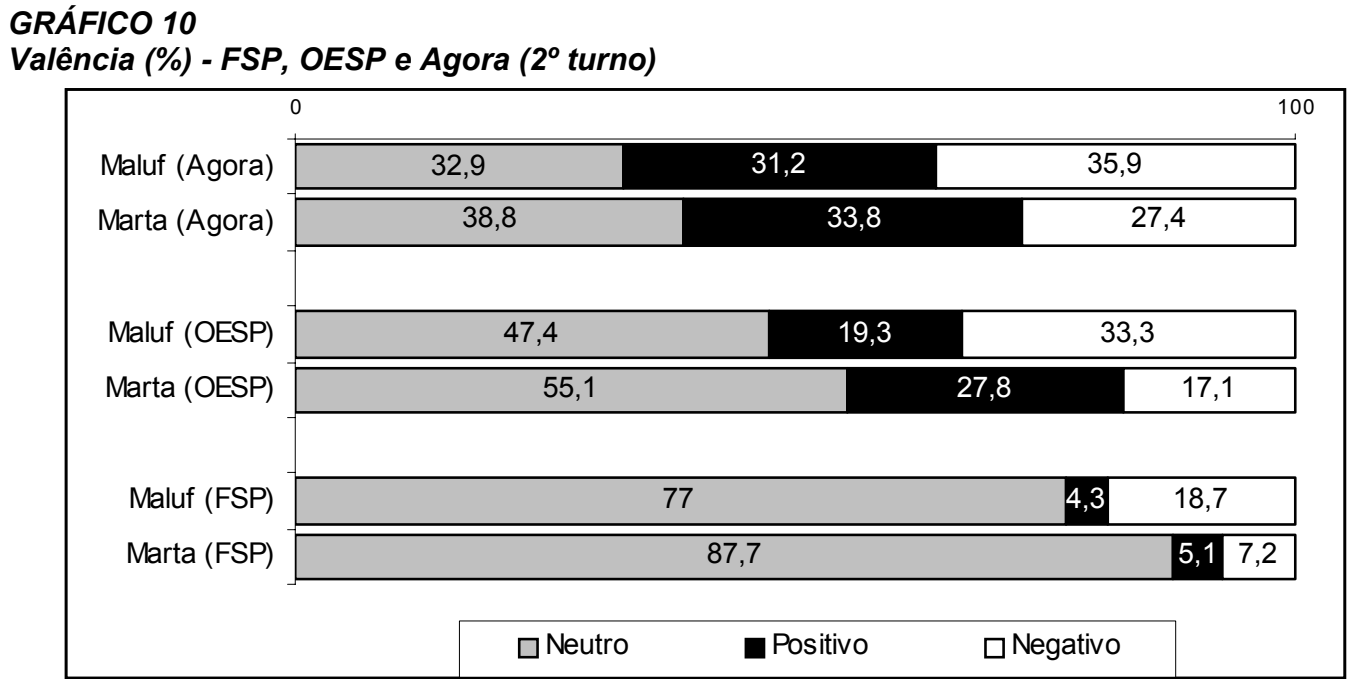

\section{Resumo e conclusão}

Sinteticamente o que se pode concluir dos números apresentados pela pesquisa? Em primeiro lugar, considerando-se apenas a cobertura eleitoral do $1^{\circ}$ turno, os dados mostram que os três dos maiores e mais representativos jornais paulistas comportaram-se de acordo com o padrão de objetividade definido operacionalmente pela pesquisa. Em segundo lugar, agora se levando em conta apenas os números sobre a cobertura do $2^{\circ}$ turno, no momento em que a disputa foi polarizada entre Maluf e Marta a objetividade foi mantida apenas por um dos jornais. Contudo, se deve levar em conta a excepcionalidade do segundo escrutínio, pois a presença de Maluf como um dos finalistas - candidato cuja biografia é marcada por acusações recorrentes quanto à sua conduta política e lisura administrativa - acabou transformando o confronto numa competição maniqueísta de natureza moral e ética. Esta característica quase plebiscitária colocou em segundo plano as diferenças programáticas e ideológicas entre os dois candidatos, prejudicando, assim, a avaliação do comportamento da mídia diante do confronto partidário.

De qualquer maneira os dados aqui apresentados, especialmente os referentes ao $1^{\circ}$ turno, não corroboram a visão bastante difundida de que a imprensa, seja pela sua natureza comercial, seja pelas ligações políticas de seus proprietários, está sempre condenada a defender os interesses dos grupos dominantes. Pelo menos no contexto paulista e no âmbito de uma disputa municipal, os números sugerem que poderemos estar diante de um saudável processo de distanciamento e neutralidade da imprensa em 
relação aos candidatos e partidos políticos. Mas é absolutamente razoável argumentar que o padrão de objetividade da imprensa nas coberturas eleitorais só pode ser testado plenamente em competições não-municipais, como as eleições para o governo do Estado e a presidência da República, em que os constrangimentos externos à rotina produtiva dos jornais certamente assumem graus e formas diferentes das pressões locais e as agendas se tornam muito mais complexas do ponto de vista político, ideológico e econômico. É o que faremos em 2002.

\section{BIBLIOGRAFIA}

ALBUQUERQUE, Afonso de. (1999a) "Aqui você vê a verdade na TV": a propaganda política na televisão. Niterói, Publicações do MCII/Universidade Federal Fluminense.

(1999b) Um outro quarto poder: imprensa e compromisso político no Brasil, comunicação apresentada no GT Mídia, Eleição e Opinião Pública, XXIII Encontro Anual da ANPOCS.

AZEVEDO, Fernando. (2000) Imprensa, campanha presidencial e agenda da mídia. In: RUBIM, Antonio Albino Canelas (org.), Mídia e Eleições 98, Salvador, Edições FACOM, pp. 31-56.

BOURDIEU, Pierre. (1997) Sobre a Televisão. Rio de Janeiro, Jorge Zahar Editores.

DAHL, Robert. (1971) Polyarchy: participation and opposition. New Haven, Yale University Press.

HABERMAS, Jürgen. (1984) Mudança Estrutural da Esfera Pública. Rio de Janeiro, Tempo Brasileiro.

HOFFMAN, B. (1985) On the Development of Materialist Theory of Mass Communication in West Germany, Media Culture and Society, vol. 15, $\mathrm{n}^{\circ} 1$.

HOWLETT, Michael. (2000) A Dialética da Opinião Pública: Efeitos Recíprocos da Política Pública e da Opinião Pública em Sociedades Democráticas Contemporâneas, Opinião Pública, vol. VI, n², Campinas.

IYENGAR, Shanto \& SIMON, Adam F. (2000) New perspectives and evidence on political communication and campaign effects Annu. Rev. Psychol. 51, pp. 149-169.

KERBEL, M. R. (1994) Edited for Television/CNN, ABC, and the 1992 Presidential Campaign, Colorado \& Oxford, Westview Press.

LANG, G. E. \& LANG, K. (1983) The battle for public opinion: the president, the press and the polls during Watergater. New York, Columbia University Press.

LAZARSFELD, BERELSON \& GOUDET. (1968) The People's Choice - How the Voter Makers Up His Mind in a Presidential Campaign, New York and London, Columbia University Press.

LIPPMANN, Walter. (1997) Public Opinion, New York, Free Press Paperbacks (1 ${ }^{a}$ edição: 1922).

LUHMANN, Niklas. (1997) A nova teoria dos sistemas. Porto Alegre, Editora da Universidade/Goethe-Institut.

MAINWARING, Scott. (1991) Políticos, Partidos e Sistemas Eleitorais. O Brasil numa Perspectiva Comparativa, Novos Estudos CEBRAP, $\mathrm{n}^{\circ} 29$, março, pp. 34-58.

MANIN, Bernard. (1995) As Metamorfoses do Governo Representativ, RBCS, $\mathrm{n}^{\circ} 29$. 
MCCOMBS, M. \& SHAW, D. (1993) The evolution of agenda-setting research: twenty-five years in the marketplace of ideas. Journal of Communication, vol. 43, $n^{\circ} 3 . p p .58-67$

Quaterly, vol. 36, n², pp.176-87

(1972) The Agenda-setting function of mass media. Public Opinion

MIGUEL, Luiz Felipe. (2000) Um ponto cego nas teorias da democracia: os meios de comunicação. BIB - Revista Brasileira de Informação Bibliográfica em Ciências Sociais, Rio de Janeiro, $n^{\circ} 49$, pp. 51-78.

NEUMANN-NOELLE, Elizabeth. (1995) La Espiral del Silencio - Opinión Pública: Nuestra Piel Social, Barcelona, Paidós.

RUBIM, Antonio Albino Canelas \& AZEVEDO, Fernando. (1998) Mídia e Política no Brasil: Textos e Agenda de Pesquisa, Lua Nova- Revista de Cultura e Política, nº 43, pp.189-216.

SARTORI, Goovanni. (1998) Homo Videns: la sociedade teledirigida. Buenos Aires, Taurus. . (1987) A Teoria da Democracia Revisitada. (vol. I). São Paulo, Editora Ática.

SCHMITT, Rógério. (2000) Partidos Políticos no Brasil (1945-2000). Rio de Janeiro, Jorge Zahar Editores.

SCHUDSON, Michael. (1995) The power of news. Cambridge (mass.), Havard University Press.

SOUZA, Maria do Carmo Campelo de. (1976) Estado e Partidos Políticos no Brasil (1930 a 1964). São Paulo, Editora Alfa-Omega.

TUCHMAN, Guy. (1993) A objetividade como ritual estratégico: uma análise das noções de objetividade dos jornalistas. In: TRAQUINA, Nelson (org.), Jornalismo: questões, teorias e "estórias". Lisboa, Veja, pp.61-73.

(1978) Making News: a study in the construction of reality. New York, The Free

Press. 